\title{
Eating out of home and obesity: a Brazilian nationwide survey
}

\author{
Ilana Nogueira Bezerra* and Rosely Sichieri \\ Department of Epidemiology, Institute of Social Medicine, State University of Rio de Janeiro, Rua São Francisco \\ Xavier 524, $7^{\circ}$ andar, Bloco E, CEP 20550-012, Rio de Janeiro, R, Brazil
}

Submitted 6 November 2008: Accepted 26 March 2009: First published online 12 May 2009

\begin{abstract}
Objective: The aim of the present study was to investigate the relationship between out-of-home $(\mathrm{OH})$ eating and overweight and obesity among adults in Brazil.

Design: Data were based on the 2002-2003 Household Budget Survey (48 470 households) conducted by The Brazilian Census Bureau. Foods and drinks purchased for $\mathrm{OH}$ eating during a one-week period were recorded by each participant. We considered $\mathrm{OH}$ eating as the purchase of at least one food or drink item for $\mathrm{OH}$ consumption during this period. We classified items as: soft drinks, deep-fried snacks, fast foods, sweets and sit-down meals.

Setting: Urban areas in Brazil.

Subjects: 56178 participants (26225 men and 29953 women), aged 25-65 years. Results: The weighted prevalence of $\mathrm{OH}$ eating was $40 \cdot 3 \%$. Overall, $\mathrm{OH}$ eating was positively associated with overweight $(\mathrm{OR}=1 \cdot 21 ; 95 \% \mathrm{CI} 1 \cdot 10,1 \cdot 33)$ and obesity $(\mathrm{OR}=1 \cdot 35 ; 95 \% \mathrm{CI} 1 \cdot 16,1 \cdot 57)$ among men, but not among women. Sit-down meals and soft drinks were the most frequently reported food groups. Both were positively associated with overweight ( $\mathrm{OR}=1 \cdot 34$ for meals; $\mathrm{OR}=1 \cdot 17$ for soft drinks, $P<0.05)$ and obesity $(\mathrm{OR}=1.51$ for meals; $\mathrm{OR}=1.39$ for soft drinks, $P<0 \cdot 05)$ among men, but negatively associated with overweight and obesity among women.

Conclusions: $\mathrm{OH}$ eating was associated with overweight and obesity only among men, whereas, among women, eating sit-down meals out of home was protective for obesity, suggesting that women make healthier food choices when they eat out of home.
\end{abstract}

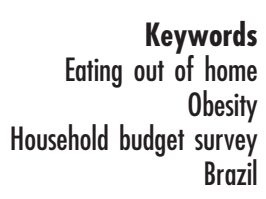

The prevalence of obesity is rising worldwide and also in Brazil $^{(1,2)}$. In 2003, $40 \%$ of Brazilian adults (over 20 years of age) presented body weight excess (BMI $\left.>25 \mathrm{~kg} / \mathrm{m}^{2}\right)$ and $11 \cdot 1 \%$ were obese $\left(\mathrm{BMI} \geq 30 \mathrm{~kg} / \mathrm{m}^{2}\right)$. The prevalence of obesity in Brazil has been shown to increase along with income among men, while among women this relationship is curvilinear $^{(2)}$, i.e. prevalences increase in the low-income groups and then decrease in the other income groups.

The causes of increased obesity are not well defined. Although obesity is a multifactorial disease, dietary intake plays an important role in its development. In Brazil, a household food availability survey in 2002-2003 revealed an energy intake of $7112 \cdot 8 \mathrm{~kJ}(1700 \mathrm{kcal})$ in urban areas ${ }^{(3)}$. This intake did not consider the amount of food eaten out of home, suggesting that an important source of energy intake comes from food eaten away from home, in view of the fact that obesity rates are increasing in Brazil. In the USA, the contribution of food prepared away from home to total energy intake increased from $18 \%$ to $32 \%$ from 1978 to $1996^{(4)}$. Therefore, increased consumption of food away from home has been pointed as one of the causes for the obesity epidemic ${ }^{(5)}$. Some cross-sectional and longitudinal studies have shown an association between eating out and/or the frequency of eating out, especially at fast-food restaurants, and BMI or weight gain $^{(5-9)}$. However, in other studies, this association was either not found ${ }^{(10)}$ or it was found only among men ${ }^{(11)}$ or only among women ${ }^{(12)}$.

The high energy density and fat contents of foods eaten out of home is a possible explanation for this behaviour being a risk factor for obesity ${ }^{(4,10)}$. In addition, reduced physical activity was associated with increased frequency of out-of-home $(\mathrm{OH})$ eating ${ }^{(10)}$.

There are no studies focusing on the association between eating out and obesity in developing countries. $\mathrm{OH}$ eating has been considered to have an influence on the increasing rates of overweight and obesity in Brazil $^{(13)}$, but as of yet, there has been no direct evidence supporting this assertion.

The level of spending on eating away from home in the USA rose from $26 \%$ of total food expenditures in the 1970 s, to $39 \%$ in 1996 , and it reached $42 \%$ in $2002^{(14,15)}$. 
In metropolitan areas of Brazil, this spending has increased from $25 \cdot 4 \%$ to $29 \cdot 7 \%$ from the $1995-1996$ to the 2002-2003 Household Budget Survey (HBS) ${ }^{(2,16)}$.

Using data collected in the last Brazilian HBS carried out in 2002-2003 (48470 households), we investigated the relationship between $\mathrm{OH}$ eating and the prevalence of overweight and obesity.

\section{Methods}

This study was based on the 2002-2003 HBS conducted by The Brazilian Census Bureau (Instituto Brasileiro de Geografia e Estatística - IBGE). The detailed methodology has been previously described ${ }^{(2)}$. In short, the 2002-2003 Brazilian HBS was conducted during twelve consecutive months - in order to capture seasonal variations - on a national sample of 48470 households using a two-stage sampling. In the first stage, primary sampling units (PSU) were selected by systematic sampling with proportional probability to the number of households. In the second stage, households were selected by simple random sampling without reposition. The survey's household non-response rate was $20 \cdot 4 \%$. Only $2 \cdot 0 \%$ refused to participate, and the greatest percentage of nonresponse (9.9\%) was due to not finding any residents at home in three visits to the household.

For the present study, only data from urban areas were included. Individuals less than 25 years of age were excluded from the analysis because it is usually from that age that people become completely responsible for their food expenditures. Those aged 65 years and over were also excluded because BMI has been found to be less informative of health risks and mortality in the elderly population ${ }^{(17)}$. We did not consider pregnant and lactating women, leaving for analysis 61064 individuals. Of those, 4886 individuals (8.0\%) had missing values for BMI, yielding a final sample size of 56178 subjects (26225 men and 29953 women).

\section{Measurements}

\section{BMI}

Weight was measured to the nearest $0 \cdot 1 \mathrm{~kg}$ by using an electronic portable scale, and height was measured with a vertical wall-mounted stadiometer. BMI was estimated as weight (in $\mathrm{kg}$ )/ height $^{2}$ (in $\mathrm{m}$ ), and WHO classification ${ }^{(18)}$ was used: underweight $\left(\mathrm{BMI}<18.5 \mathrm{~kg} / \mathrm{m}^{2}\right)$, normal $\left(18.5 \mathrm{~kg} / \mathrm{m}^{2} \leq \mathrm{BMI}<25 \mathrm{~kg} / \mathrm{m}^{2}\right)$, overweight $\left(25 \mathrm{~kg} / \mathrm{m}^{2} \leq\right.$ $\mathrm{BMI}<30 \mathrm{~kg} / \mathrm{m}^{2}$ ) and obese $\left(\mathrm{BMI} \geq 30 \mathrm{~kg} / \mathrm{m}^{2}\right)$. However, due to the small percentage of individuals in the first category $(3 \cdot 3 \%)$, the first two groups were combined.

\section{Out-of-bome eating}

HBS collects individual expenditure data regarding all food items purchased out of home during a one-week period. A diary is used for recording $\mathrm{OH}$ individual expenditures. Each member of the household was requested to keep a record of all food and drink items purchased for $\mathrm{OH}$ consumption, the cost and the place of purchase during a $7 \mathrm{~d}$ period. Individuals could choose to combine several purchases of the same item during the week into a single entry, with the total amount paid during the $7 \mathrm{~d}$ period. Therefore, for the present study, we considered someone to have engaged in $\mathrm{OH}$ eating if that person had registered at least one purchase for $\mathrm{OH}$ consumption of a food or drink item during the week.

Foods eaten out that have been considered risk factors for obesity, such as soft drinks ${ }^{(19,20)}$, deep-fried snacks ${ }^{(21,22)}$, fast foods ${ }^{(6,7)}$ and sweets ${ }^{(23)}$ were analysed in association with the BMI classification. 'Deep-fried snacks' refer to common street foods made of dough filled with an option of chicken, meat, cheese, ham, etc. 'Fast foods' refer to hamburgers, cheeseburgers, pizza, french fries, hot dogs and sandwiches in general. 'Sweets' refers to candies, chocolates, ice cream, milk shakes and other sweet desserts. This food group was chosen because Brazil is the world's largest producer and the second greatest consumer of sugar, and $45 \%$ of sugar intake comes from industrialised products ${ }^{(24)}$. 'Sit-down meals' in Brazil refer to dishes regularly eaten for lunch and dinner, and are used for the purposes of this study as a contrast to snacks and fast food. Brazilian traditional sit-down meals usually include rice and beans, a dietary pattern associated with lower risk of overweight/obesity ${ }^{(25)}$. Thus, we include 'sit-down meals' as a food category, due to its possible protective factor for obesity.

\section{Data analysis}

Per-capita household income includes both monetary and non-monetary incomes, such as gifts or donations of all types, transfers among family members, benefits provided by the government or the community, etc. It was stratified as: up to $\frac{1}{2}$ minimal wage, between $\frac{1}{2}$ and 2 minimal wages, between 2 and 5 minimal wages and more than 5 minimal wages. The value of the minimal wage practised on 15 January 2003 was adopted (R \$ 200 in Brazilian currency, approximately U\$ 65). Participants were stratified in ten-year age groups.

All statistical analyses were performed separately for men and women, using the survey procedure in the statistical software SAS, version 9·1 (SAS Institute Inc., Cary, NC, USA). Frequencies and prevalences were weighted, and statistical analyses took into account the sample design effect.

Logistic regression models test associations between overweight/obesity and both age and income groups. The models were created using generalised logit function, comparing both overweight and obesity categories with the reference category (normal weight). We evaluated linear and quadratic associations. Among women, for income, both linear and quadratic terms were statistically significant, indicating a curvilinear association, with greater prevalences at median income. 
The prevalence of $\mathrm{OH}$ intake of soft drinks, deep-fried snacks, fast foods, sweets and sit-down meals was calculated considering all the consumers of each food group divided by the total sample.

We also calculated the OR of being overweight and obesity associated with $\mathrm{OH}$ eating with logistic regression models. The models were adjusted for age and per-capita household income as continuous variables. The adjustment for income among women included income and income squared. The same procedures were used to examine the relationships between overweight and obesity and food groups eaten out of home.

The mean amount of money spent on each food group during the $7 \mathrm{~d}$ period was based on the sum of the amounts spent on each group divided by all the individuals who purchased items from that food group.

\section{Results}

The overall prevalence of $\mathrm{OH}$ eating $(40 \cdot 3 \%)$ was greater among men compared to women $(46 \cdot 8 \%$ v. 34.5\%, $P<0 \cdot 0001)$. In general, $\mathrm{OH}$ eating prevalences decreased with age and increased with income. The same pattern was observed for each food group (data not shown). Among men, $\mathrm{OH}$ eating was positively associated to fatness, with $50 \%$ of those who are obese, $48 \%$ of those overweight and
$45 \%$ of those with normal weight eating out, whereas normal-weight women showed the highest prevalence of $\mathrm{OH}$ eating (37.5\%), while overweight and obese women presented lower, similar prevalences (30\%).

The prevalence of overweight was 38.5\% and the prevalence of obesity was $11.9 \%$ among men, and for women, these values were $24.6 \%$ and $12.5 \%$, respectively. Men who ate out of home presented higher prevalences of overweight and obesity than those who did not eat out $(38.5 \% v .36 \cdot 1 \%$ for overweight and $11.9 \% v$. $10 \cdot 3 \%$ for obesity). In contrast, women who ate out of home presented lower prevalences of both overweight and obesity than those who did not eat out of home (24.6\% v. 29.8\% for overweight and $12 \cdot 5 \% v .15 \cdot 0 \%$ for obesity).

Prevalences of overweight and obesity by age and income according to $\mathrm{OH}$ eating are shown in Table 1. Except for the 55-64-year-old age group, men who ate out presented higher prevalences of overweight and obesity than those who did not eat out of home. Among women, the opposite was observed: women who ate out of home presented lower prevalences of overweight and obesity than those who did not eat out. For both men and women, overweight and obesity were positively associated with age. Income showed a great and positive association with overweight and obesity, especially in men, and a quadratic association in women (Table 1).

Table 1 Weighted prevalences of overweight and obesity by age and income (in minimal wages - MW) according to out-of-home (OH) eating. Brazil - urban area, 2002-2003

\begin{tabular}{|c|c|c|c|c|}
\hline & \multicolumn{4}{|c|}{$\mathrm{OH}$ eating } \\
\hline & \multicolumn{2}{|c|}{ No $(n$ 35816) } & \multicolumn{2}{|c|}{ Yes (n 20362) } \\
\hline & Overweight & Obesity & Overweight & Obesity \\
\hline & & & & \\
\hline \multicolumn{5}{|l|}{ Age (years) } \\
\hline $25-34$ & $31 \cdot 8$ & $6 \cdot 8$ & $33 \cdot 2$ & $8 \cdot 6$ \\
\hline $35-44$ & $36 \cdot 4$ & $10 \cdot 0$ & $40 \cdot 7$ & $14 \cdot 3$ \\
\hline $45-54$ & $40 \cdot 4$ & $13 \cdot 5$ & $42 \cdot 6$ & $14 \cdot 0$ \\
\hline $55-64$ & 38.5 & $13 \cdot 5$ & $44 \cdot 4$ & $13 \cdot 4$ \\
\hline$P$ value of trend & $<0.0001$ & $<0.0001$ & $<0.0001$ & $<0.0001$ \\
\hline \multicolumn{5}{|l|}{ Per-capita household income } \\
\hline Up to $\frac{1}{2} \mathrm{MW}$ & $25 \cdot 1$ & $4 \cdot 0$ & $28 \cdot 0$ & $5 \cdot 0$ \\
\hline$\frac{1}{2}$ to $2 \mathrm{MW}$ & $34 \cdot 8$ & $10 \cdot 1$ & 33.9 & $10 \cdot 7$ \\
\hline 2 to $5 \mathrm{MW}$ & $40 \cdot 9$ & $12 \cdot 8$ & $40 \cdot 3$ & $12 \cdot 4$ \\
\hline 5 or more MW & $45 \cdot 1$ & $13 \cdot 5$ & $45 \cdot 9$ & $15 \cdot 0$ \\
\hline \multirow[t]{2}{*}{$P$ value of trend } & $<0.0001$ & $<0.0001$ & $<0.0001$ & $<0.0001$ \\
\hline & \multicolumn{4}{|c|}{ Women } \\
\hline \multicolumn{5}{|l|}{ Age (years) } \\
\hline $25-34$ & $22 \cdot 5$ & $9 \cdot 5$ & $17 \cdot 5$ & $8 \cdot 4$ \\
\hline $35-44$ & $29 \cdot 1$ & $13 \cdot 2$ & $26 \cdot 1$ & $11 \cdot 8$ \\
\hline $45-54$ & $34 \cdot 5$ & $18 \cdot 4$ & $32 \cdot 2$ & $18 \cdot 9$ \\
\hline $55-64$ & $37 \cdot 1$ & $22 \cdot 6$ & $33 \cdot 5$ & $20 \cdot 4$ \\
\hline$P$ value of trend & $<0.0001$ & $<0.0001$ & $<0.0001$ & $<0.0001$ \\
\hline \multicolumn{5}{|l|}{ Per-capita household income } \\
\hline Up to $\frac{1}{2} \mathrm{MW}$ & $27 \cdot 7$ & $13 \cdot 3$ & $24 \cdot 6$ & $11 \cdot 0$ \\
\hline$\frac{1}{2}$ to $2 \mathrm{MW}$ & $30 \cdot 8$ & $15 \cdot 2$ & $26 \cdot 5$ & $13 \cdot 7$ \\
\hline 2 to $5 \mathrm{MW}$ & $30 \cdot 7$ & $16 \cdot 1$ & $24 \cdot 6$ & $12 \cdot 9$ \\
\hline 5 or more $\mathrm{MW}$ & $26 \cdot 4$ & $13 \cdot 6$ & $21 \cdot 7$ & $10 \cdot 6$ \\
\hline$P$ value of quadratic trend* & 0.0004 & 0.005 & 0.08 & 0.04 \\
\hline
\end{tabular}

${ }^{*}$ Quadratic association includes income group and income group squared. 
Table 2 OR and $95 \% \mathrm{Cl}$ (adjusted for age and per-capita household income) of being overweight or obese associated with out-of-home eating. Brazil - urban area, 2002-2003

\begin{tabular}{|c|c|c|c|c|c|}
\hline \multirow[b]{2}{*}{ Gender } & \multirow[b]{2}{*}{ BMI classification } & \multicolumn{2}{|c|}{ Adjusted for age* } & \multicolumn{2}{|c|}{ Adjusted for age* and incomet } \\
\hline & & OR & $95 \% \mathrm{Cl}$ & OR & $95 \% \mathrm{Cl}$ \\
\hline \multirow[t]{3}{*}{ Men } & Normal & $1 \cdot 00$ & - & $1 \cdot 00$ & - \\
\hline & Overweight & $1 \cdot 21$ & $1 \cdot 10,1 \cdot 33$ & $1 \cdot 12$ & $1 \cdot 02,1 \cdot 24$ \\
\hline & Obesity & 1.35 & $1 \cdot 16,1.57$ & $1 \cdot 23$ & $1 \cdot 05,1.43$ \\
\hline \multirow[t]{3}{*}{ Women } & Normal & $1 \cdot 00$ & - & $1 \cdot 00$ & - \\
\hline & Overweight & $0 \cdot 82$ & $0.74,0.90$ & $0 \cdot 88$ & $0.80,0.97$ \\
\hline & Obesity & 0.87 & $0.76,0.99$ & 0.94 & $0.82,1.07$ \\
\hline
\end{tabular}

${ }^{*}$ Age as a continuous variable.

tIncome as a continuous variable (includes income for men and women and income squared for women).

$\mathrm{OH}$ eating was positively associated with overweight and obesity in men, but among women, $\mathrm{OH}$ eating did not show a positive association with either overweight or obesity (Table 2).

The prevalence of $\mathrm{OH}$ intake according to selected food groups indicated that sit-down meals and soft drinks were the groups most frequently eaten outside home, for both men and women (Table 3). Compared to women, men had a higher consumption of all food groups, except for sweets.

Table 4 shows the age-adjusted OR of the relationship between overweight and obesity and food groups eaten out of home. Among men, the intake of soft drinks and sit-down meals was positively associated with overweight and obesity. For women, a negative association between overweight and intake of soft drinks was observed, and the intake of sit-down meals was shown to be protective for both overweight and obese women. The intake of fast food and deep-fried snacks presented no association with the prevalences of overweight and obesity among women, and the intake of sweets was associated with neither overweight nor obesity for either gender.

Expenditures on sit-down meals eaten away from home presented the highest costs. They were almost three times as high as the expenditures on fast food, and eight times as high as those on deep-fried snacks (Table 5).

\section{Discussion}

In Brazil, $\mathrm{OH}$ eating was positively associated with overweight and obesity among men, but not among women. Soft drinks and sit-down meals had the highest frequencies of consumption away from home, and the $\mathrm{OH}$ intake of these groups was positively associated with overweight and obesity only among men.

Overall, our findings did not show a positive relationship between the prevalence of obesity and $\mathrm{OH}$ eating among women; however, other studies have shown that women who report high frequency of eating out during a week have poorer quality of diet, with a higher intake of
Table 3 Frequency of food groups eaten out of home (\%) according to gender and BMI classification. Brazil - urban area, 2002-2003

\begin{tabular}{llrr}
\hline Food group & BMI classification & Men & Women \\
\hline Soft drinks & Overall & $16 \cdot 1$ & $10 \cdot 9$ \\
& Normal & $15 \cdot 3$ & $12 \cdot 2$ \\
& Overweight & $16 \cdot 5$ & $8 \cdot 9$ \\
Fast food & Obesity & $18 \cdot 5$ & $9 \cdot 4$ \\
& Overall & $9 \cdot 6$ & $7 \cdot 2$ \\
& Normal & $9 \cdot 2$ & $8 \cdot 0$ \\
& Overweight & $10 \cdot 2$ & $5 \cdot 8$ \\
Deep-fried snacks & Obesity & $9 \cdot 9$ & $6 \cdot 5$ \\
& Overall & $10 \cdot 3$ & $9 \cdot 0$ \\
& Normal & $9 \cdot 9$ & $9 \cdot 6$ \\
Sweets & Overweight & $10 \cdot 3$ & $8 \cdot 1$ \\
& Obesity & $11 \cdot 8$ & $8 \cdot 5$ \\
& Overall & $7 \cdot 0$ & $10 \cdot 3$ \\
Sit-down meals & Normal & $7 \cdot 1$ & $10 \cdot 8$ \\
& Overweight & $6 \cdot 7$ & $9 \cdot 2$ \\
& Obesity & $8 \cdot 0$ & $10 \cdot 5$ \\
& Overall & $18 \cdot 5$ & $12 \cdot 4$ \\
& Normal & $16 \cdot 4$ & $14 \cdot 2$ \\
& Overweight & $20 \cdot 3$ & $9 \cdot 9$ \\
& Obesity & $22 \cdot 0$ & $9 \cdot 9$ \\
\hline
\end{tabular}

total energy, fat and sodium ${ }^{(9,26)}$, especially when they eat at fast-food restaurants ${ }^{(9)}$.

Our data showed a high proportion of sit-down meals eaten out of home, which are usually healthier than fast food. At least among women, eating sit-down meals away from home was negatively associated with overweight or obesity. Sit-down meals were the most frequently reported item among women, which may indicate healthier choices compared to deep-fried snacks or fast food. Costs on sit-down meals out of home were eight times as high as those on deep-fried snacks and almost three times as high as those on fast food. In this line, women at higher social and economic levels had lower prevalence of overweight/obesity.

Evidences of association between consumption of food away from home and obesity are not consistent; however, food prepared away from home tends to be significantly higher in energy ${ }^{(27,28)}$, saturated fat content, sodium ${ }^{(4)}$ and sugar ${ }^{(29)}$, and poorer in calcium, fibre, iron and vitamins ${ }^{(4,29)}$. They also present bigger - and increasing - portion sizes, 
Table 4 Age-adjusted ${ }^{*}$ OR of overweight and obesity and $95 \% \mathrm{Cl}$ according to food groups. Brazil - urban area, 2002-2003

\begin{tabular}{|c|c|c|c|c|c|}
\hline \multirow[b]{2}{*}{ Food Groups } & \multirow[b]{2}{*}{ BMI classification } & \multicolumn{2}{|c|}{ Men } & \multicolumn{2}{|c|}{ Women } \\
\hline & & OR & $95 \% \mathrm{Cl}$ & OR & $95 \% \mathrm{Cl}$ \\
\hline \multirow{3}{*}{ Soft drinks } & Normal & $1 \cdot 00$ & - & $1 \cdot 00$ & - \\
\hline & Overweight & $1 \cdot 17$ & $1 \cdot 02,1 \cdot 33$ & $0 \cdot 80$ & $0.68,0.93$ \\
\hline & Obesity & $1 \cdot 39$ & $1 \cdot 15,1 \cdot 70$ & $0 \cdot 88$ & $0 \cdot 70,1 \cdot 10$ \\
\hline \multirow[t]{3}{*}{ Fast food } & Normal & $1 \cdot 00$ & - & $1 \cdot 00$ & - \\
\hline & Overweight & $1 \cdot 20$ & $1 \cdot 01,1 \cdot 42$ & 0.79 & $0.64,0.97$ \\
\hline & Obesity & $1 \cdot 20$ & $0.93,1.56$ & 0.94 & $0.71,1 \cdot 25$ \\
\hline \multirow[t]{3}{*}{ Deep-fried snacks } & Normal & $1 \cdot 00$ & - & $1 \cdot 00$ & - \\
\hline & Overweight & $1 \cdot 09$ & $0.93,1.28$ & 0.95 & $0 \cdot 80,1 \cdot 13$ \\
\hline & Obesity & $1 \cdot 30$ & $1 \cdot 03,1 \cdot 65$ & $1 \cdot 04$ & $0.84,1 \cdot 29$ \\
\hline \multirow[t]{3}{*}{ Sweets } & Normal & 1.00 & - & 1.00 & - \\
\hline & Overweight & 0.97 & $0 \cdot 80,1 \cdot 18$ & 0.98 & $0 \cdot 84,1 \cdot 14$ \\
\hline & Obesity & $1 \cdot 24$ & $0.92,1.67$ & $1 \cdot 20$ & $0.98,1.47$ \\
\hline \multirow[t]{3}{*}{ Sit-down meals } & Normal & $1 \cdot 00$ & - & $1 \cdot 00$ & - \\
\hline & Overweight & $1 \cdot 34$ & $1 \cdot 18,1 \cdot 51$ & $0 \cdot 73$ & $0.63,0.84$ \\
\hline & Obesity & $1 \cdot 51$ & $1 \cdot 26,1 \cdot 81$ & $0 \cdot 76$ & $0.61,0.94$ \\
\hline
\end{tabular}

${ }^{*}$ Age as a continuous variable.

Table 5 Mean and SD of expenditure during a one-week period in Brazilian currency $(\mathrm{R} \$)$ on the acquisition of food groups eaten out of home. Brazil - urban area, 2002-2003

\begin{tabular}{lcc}
\hline Food groups & Mean $(\mathrm{R} \$)$ & $\mathrm{SD}$ \\
\hline Soft drinks & 3.39 & 0.07 \\
Fast food & 9.60 & 0.37 \\
Deep-fried snacks & 3.21 & 0.13 \\
Sweets & 2.24 & 0.08 \\
Sit-down meals & 24.93 & 0.79 \\
\hline
\end{tabular}

which can contribute to an excessive consumption of energy $^{(30,31)}$.

Our data also showed that drinking soft drinks out of home was negatively associated with overweight among women. The secular trend of prevalence of obesity in Brazil is gender-specific, with no increase in the most recent survey among women, and with a sharp increase among men ${ }^{(32)}$, indicating that women may be changing their eating behaviour to curb the obesity epidemic. The HBS did not differentiate no-calorie drinks from regular soft drinks, which could explain this negative association.

We found an association between all food groups eaten out of home and overweight and obesity among men, except for the 'sweets' group. McCrory et al. (1999) showed that the frequency of restaurant food consumption was positively associated with increased body weight in adults ${ }^{(8)}$. Bowman and Vinyard (2004) demonstrated a positive association between fast food consumption and weight excess ${ }^{(33)}$, and the frequency of eating at fast-food restaurants was also associated with obesity ${ }^{(34)}$. Our data showed that even for sit-down meals eaten out of home, a positive association is observed with overweight (OR = 1.34) and obesity $(O R=1 \cdot 51)$ among men. Sit-down meals eaten away from home were the item with the highest association with obesity for this gender. Therefore, the hypothesis that fast food is a major risk factor for excessive energy intake is not supported by this large Brazilian data set. When studying the association between
BMI and the frequency of eating at non-fast-food restaurants, Jeffery et al. (2006) did not find an association; but Binkley et al. (2000) demonstrated that foods from restaurants as well as from fast-food outlets were a significant determinant of BMI among men ${ }^{(5,6)}$.

Selective under-reporting of $\mathrm{OH}$ eating, mainly among obese women, has been observed in other studies using direct methods of assessing food consumption ${ }^{(35,36)}$. This bias is less probable in our findings since budget data may be less prone to under-reporting, although this is still a possibility.

Our definition for $\mathrm{OH}$ eating considered at least one episode of eating out during a week, since individual daily measurements were not available for all participants. Also, budget data do not have enough details regarding what was eaten, such as specific information on the quantity or the frequency during the week. Furthermore, by design, HBS does not consider foods prepared outside the home which were eaten at home, such as take-away and delivery - foods which are known to be rich in fat and energy ${ }^{(14)}$. Therefore, association with frequency of $\mathrm{OH}$ eating, a more reliable measurement of energy consumed, was not possible.

On the other hand, $\mathrm{OH}$ eating may not be a major independent factor contributing to obesity. Behaviours that contribute to an overconsumption of food energy, such as easy availability of inexpensive foods, highenergy-density foods and a higher food portion size, occur for both at-home and $\mathrm{OH}$ consumption ${ }^{(30,37,38)}$.

In conclusion, $\mathrm{OH}$ eating was associated with overweight/obesity only among men, suggesting that the promotion of healthy eating habits targeting consumer behaviours and food choices may have been more effective for women. Gender, as well as age and income, presented an important role in $\mathrm{OH}$ eating. Costs are also relevant, since eating sit-down meals out of home is almost three times more expensive than eating other items, such as fast foods. Possible policies could include 
public campaigns addressing the message in an understandable way for both men and women, or even subsidies that would help reduce the price of low-energy, high-nutrient-density foods. Finally, additional studies, particularly with longitudinal analyses, are needed to fully explore the consumption away from home as a risk factor for obesity, especially because this consumption is increasing.

\section{Acknowledgements}

The study was funded by the Research Council of State of Rio de Janeiro (FAPERJ). None of the authors have conflicts of interest. Both the authors contributed to the design of the study. I.N.B. contributed to analysing and interpreting the data, and drafting the manuscript. R.S. conducted data analysis and interpretation, and both authors read and approved the final manuscript. The authors thank André Martins from The Brazilian Census Bureau for providing support to the study.

\section{References}

1. World Health Organization (2003) Diet, Nutrition and the Prevention of Chronic Diseases. Joint WHO/FAO Expert Consultation. WHO Technical Report Series no. 916. Geneva: WHO.

2. Instituto Brasileiro de Geografia e Estatística (2004) National Household Budget Survey 2002-2003: Analyses on Household Food Availability and Nutrition Status in Brazil (in Portuguese). Rio de Janeiro: IBGE.

3. Levy-Costa RB, Sichieri R, Pontes NS \& Monteiro CA (2005) Household food availability in Brazil: distribution and trends (1974-2003). Rev Saude Publica 39, 530-540.

4. Guthrie JF, Lin BH \& Frazao E (2002) Role of food prepared away from home in the American diet, 1977-78 versus 1994-96: changes and consequences. J Nutr Educ Behav 34, 140-150.

5. Binkley JK, Eales J \& Jekanowski M (2000) The relation between dietary change and rising US obesity. Int $J$ Obes Relat Metab Disord 24, 1032-1039.

6. Jeffery RW, Baxter J, McGuire M \& Linde J (2006) Are fast food restaurants an environmental risk factor for obesity? Int J Behav Nutr Phys Act 3, 2.

7. Duffey KJ, Gordon-Larsen P, Jacobs DR Jr, Williams OD \& Popkin BM (2007) Differential associations of fast food and restaurant food consumption with 3-y change in body mass index: the Coronary Artery Risk Development in Young Adults Study. Am J Clin Nutr 85, 201-208.

8. McCrory MA, Fuss PJ, Hays NP, Vinken AG, Greenberg AS \& Roberts SB (1999) Overeating in America: association between restaurant food consumption and body fatness in healthy adult men and women ages 19 to 80 . Obes Res 7 , 564-571.

9. French SA, Harnack L \& Jeffery RW (2000) Fast food restaurant use among women in the Pound of Prevention study: dietary, behavioral and demographic correlates. Int J Obes Relat Metab Disord 24, 1353-1359.

10. Orfanos P, Naska A, Trichopoulos D et al. (2007) Eating out of home and its correlates in 10 European countries. The European Prospective Investigation into Cancer and Nutrition (EPIC) study. Public Health Nutr 10, $1515-1525$.
11. Burns C, Jackson M, Gibbons C \& Stoney RM (2002) Foods prepared outside the home: association with selected nutrients and body mass index in adult Australians. Public Health Nutr 5, 441-448.

12. Kant AK \& Graubard BI (2004) Eating out in America, 1987-2000: trends and nutritional correlates. Prev Med 38, 243-249.

13. Mendonça CP \& Anjos LA (2004) Dietary and physical activity factors as determinants of the increase in overweight/obesity in Brazil. Cad Saude Publica 20, 698-709.

14. Lin BH, Frazão E \& Guthrie J (1999) Away-From-Home Foods Increasingly Important to Quality of American Diet. Agriculture Information Bulletin no. 749. Washington, DC: US Department of Agriculture, Economic Research Service.

15. Variyam JN (2005) Nutrition Labeling in the Food-AwayFrom-Home Sector: An Economic Assessment. Economic Research Report no. 4. Washington, DC: US Departament of Agriculture, Economic Research Service; available at http:// www.ers.usda.gov/publications/ERR4/ed

16. Instituto Brasileiro de Geografia e Estatística (1998) National Household Budget Survey 1995-1996 (in Portuguese). Rio de Janeiro: IBGE.

17. Douketis JD, Paradis G, Keller H \& Martineau C (2005) Canadian guidelines for body weight classification in adults: application in clinical practice to screen for overweight and obesity and to assess disease risk. CMAJ 172, 995-998.

18. World Health Organization, Expert Committee (1995) Physical Status: The Use and Interpretation of Anthropometry. WHO Technical Report Series no. 854. Geneva: WHO.

19. Schulze MB, Manson JE, Ludwig DS, Colditz GA, Stampfer MJ, Willett WC \& Hu FB (2004) Sugar-sweetened beverages, weight gain, and incidence of type 2 diabetes in young and middle-aged women. JAMA 292, 927-934.

20. Malik VS, Schulze MB \& Hu FB (2006) Intake of sugarsweetened beverages and weight gain: a systematic review. Am J Clin Nutr 84, 274-288.

21. Taveras EM, Berkey CS, Rifas-Shiman SL, Ludwig DS, Rockett HR, Field AE, Colditz GA \& Gillman MW (2005) Association of consumption of fried food away from home with body mass index and diet quality in older children and adolescents. Pediatrics 116, 518-524.

22. Guallar-Castillon P, Rodriguez-Artalejo F, Fornes NS et al. (2007) Intake of fried foods is associated with obesity in the cohort of Spanish adults from the European Prospective Investigation into Cancer and Nutrition. Am J Clin Nutr 86, 198-205.

23. Popkin BM \& Nielsen SJ (2003) The sweetening of the world's diet. Obes Res 11, 1325-1332.

24. Bolling C \& Suarez NR (2001) The Brazilian Sugar Industry: Recent Developments. Sugar and Sweetener Situation \& Outlook (Special Article). Washington, DC: US Department of Agriculture, Economic Research Service.

25. Sichieri R (2002) Dietary patterns and their associations with obesity in the Brazilian city of Rio de Janeiro. Obes Res 10, 42-48.

26. Clemens LH, Slawson DL \& Klesges RC (1999) The effect of eating out on quality of diet in premenopausal women. J Am Diet Assoc 99, 442-444.

27. Bell AC \& Swinburn BA (2004) What are the key food groups to target for preventing obesity and improving nutrition in schools? Eur J Clin Nutr 58, 258-263.

28. Nielsen SJ, Siega-Riz AM \& Popkin BM (2002) Trends in food locations and sources among adolescents and young adults. Prev Med 35, 107-113.

29. Kearney JM, Hulshof KF \& Gibney MJ (2001) Eating patterns - temporal distribution, converging and diverging 
foods, meals eaten inside and outside of the home implications for developing FBDG. Public Health Nutr $\mathbf{4}$, 693-698.

30. Nielsen SJ \& Popkin BM (2003) Patterns and trends in food portion sizes, 1977-1998. JAMA 289, 450-453.

31. Jeffery RW, Rydell S, Dunn CL, Harnack LJ, Levine AS, Pentel PR, Baxter JE \& Walsh EM (2007) Effects of portion size on chronic energy intake. Int J Behav Nutr Phys Act 4, 27.

32. Monteiro CA, Conde WL \& Popkin BM (2007) Incomespecific trends in obesity in Brazil: 1975-2003. Am J Public Health 97, 1808-1812.

33. Bowman SA \& Vinyard BT (2004) Fast food consumption of US adults: impact on energy and nutrient intakes and overweight status. J Am Coll Nutr 23, 163-168.

34. Satia JA, Galanko JA \& Siega-Riz AM (2004) Eating at fastfood restaurants is associated with dietary intake, demographic, psychosocial and behavioural factors among
African Americans in North Carolina. Public Health Nutr 7, 1089-1096.

35. Weber JL, Reid PM, Greaves KA, DeLany JP, Stanford VA, Going SB, Howell WH \& Houtkooper LB (2001) Validity of self-reported energy intake in lean and obese young women, using two nutrient databases, compared with total energy expenditure assessed by doubly labeled water. Eur J Clin Nutr 55, 940-950.

36. Scagliusi FB, Polacow VO, Artioli GG, Benatti FB \& Lancha AH Jr (2003) Selective underreporting of energy intake in women: magnitude, determinants, and effect of training. J Am Diet Assoc 103, 1306-1313.

37. Monsivais P \& Drewnowski A (2007) The rising cost of lowenergy-density foods. J Am Diet Assoc 107, 2071-2076.

38. Hill JO, Wyatt HR, Reed GW \& Peters JC (2003) Obesity and the environment: where do we go from here? Science $\mathbf{2 9 9}$, $853-855$. 